Zeszyty Naukowe Szkoły Głównej Gospodarstwa Wiejskiego w Warszawie

Problemy Rolnictwa Światowego tom 18 (XXXIII), zeszyt 4, 2018: 313-322

DOI: 10.22630/PRS.2018.18.4.121

Katarzyna Kwiecińska $^{1}$, Małgorzata Kosicka-Gębska ${ }^{2}$, Jerzy Gębski ${ }^{3}$

Szkoła Główna Gospodarstwa Wiejskiego w Warszawie

\title{
Wpływ wybranych źródeł informacji na poziom wiedzy konsumentów o dziczyźnie
}

\section{Influence of Selected Information Sources on the Level of Consumers Awareness of Game Meat}

\begin{abstract}
Synopsis. Zakres informacji, jakie posiada konsument, wpływa na przebieg procesu decyzyjnego podczas zakupu żywności. Istotne jest, by konsument otrzymywał dane i wiadomości odpowiadające jego potrzebom. Za cel niniejszej pracy obrano wskazanie głównych źródeł informacji, z jakich korzystają konsumenci dziczyzny w Polsce. Określono także zakres informacji istotnych dla osób dokonujących zakupu i konsumpcji dziczyzny. Stwierdzono, że Internet jest głównym medium dla najmłodszych respondentów w wieku od 25 do 35 lat, ale także dla grupy najstarszej (powyżej 55 roku życia). W odniesieniu do ogółu próby badanej, jako najcześciej wykorzystywane źródło informacji wskazano etykiety na produktach. Tematyka najbardziej pożądanych przez konsumentów informacji obejmowała: termin przydatności do spożycia, cenę oraz pochodzenie dziczyzny. W oparciu o uzyskane wyniki możliwe jest opracowanie zaleceń dotyczących sposobu przygotowania materiałów informacyjnych promujących dziczyznę.
\end{abstract}

Słowa kluczowe: dostępność informacji, dziczyzna, zachowania konsumentów

\begin{abstract}
Every information affects consumers behavior during the decision-making process. This is the main reason why the information that consumer receives should answer his needs. The aim of this paper was to indicate the information sources, that are most frequently used by game meat consumers in Poland. Also the information content was analyzed. It was found that the Internet is the main information source for the youngest respondents ( 25 to 35 years old), but also for the oldest ones (over 55 years old). Consumers searched for the information about: the shelf-life date, the price and the origin of game meat. They acquired those information from product labels. Based on the results obtained, it is possible to create recommendations for preparation of commercial materials about game meat.
\end{abstract}

Key words: availability of information, wild game meat, consumers behavior

JEL Classification: D12, D83

\footnotetext{
${ }^{1}$ mgr inż., Wydział Nauk o Żywieniu Człowieka i Konsumpcji, Szkoła Główna Gospodarstwa Wiejskiego w Warszawie, 02-776 Warszawa, ul. Nowoursynowska 159c, e-mail: katarzyna_kwiecinska@sggw.pl; https://orcid.org/0000-0002-9540-0212

${ }^{2}$ dr hab., Wydział Nauk o Żywieniu Człowieka i Konsumpcji, Szkoła Główna Gospodarstwa Wiejskiego w Warszawie, 02-776 Warszawa, ul. Nowoursynowska 159c, e-mail: malgorzata_kosicka_gebska@sggw.pl; https://orcid.org/0000-0002-2043-7627

3 dr inż., Wydział Nauk o Żywieniu Człowieka i Konsumpcji, Szkoła Główna Gospodarstwa Wiejskiego

w Warszawie, 02-776 Warszawa, ul. Nowoursynowska 159c, e-mail: jerzy_gebski@sggw.pl
} 


\section{Wstęp}

Współczesny konsument jest aktywnym członkiem społeczeństwa informacyjnego. Funkcjonuje w świecie pełnym danych, dostępnych dzięki najnowszym osiagnięciom techniki, ale także przekazywanych tradycyjnymi kanałami, wykorzystywanymi przez poprzednie pokolenia. Informacje gromadzi i przetwarza $\mathrm{w}$ procesie decyzyjnym związanym z zakupem i spożyciem żywności. Poszukiwanie informacji to drugi z pięciu etapów opracowanego w 1968 roku modelu EBK, opisującego proces podejmowania decyzji przez konsumenta (Rudnicki, 2000, s. 229).

Mnogość źródeł informacji wymaga od wszystkich jednostek funkcjonujących na rynku spożywczym skupionej uwagi i selektywnego podejścia do wiedzy (Kłosiewicz-Górecka i Słomińska, 2005). Wykorzystane powinny zostać jedyne informacje uznane przez konsumenta za potencjalnie przydatne w procesie decyzyjnym. Konsumenci jednak różnią się miedzy sobą pod względem wykazywanych potrzeb informacyjnych. Tym samym przyjąć należy, że ocena przydatności informacji jest cechą wysoce indywidualną dla każdego konsumenta. Warto także pokreślić, że posiadanie wiedzy nie zawsze wiąże się z jej wykorzystywaniem w praktyce. Rola, jaką odgrywa posiadana informacja w procesie decyzyjnym jest różna w zależności od produktu oraz cech respondenta (Maciejewski, 2010, s. 18).

\section{Przegląd literatury}

Regulacje prawne nakładają na producentów żywności obowiązek udzielania konsumentom rzetelnych informacji. Dotyczy to zarówno informacji o składzie produktu, jego charakterze, ale także potencjalnego wpływu na zdrowie, w szczególności korzyści płynących z jego spożycia czy wykorzystania w gospodarstwie domowy. Ujednolicone prawo pozwala konsumentom czuć się bezpiecznie podczas zakupów i spożycia żywności. W kontekście znakowania żywności warto poruszyć problem zakupu żywności porcjowanej, pozbawionej zbiorczego opakowania, zawierającego podstawowe informacje, czy etykiety. W taki sposób nabywane mogą być produkty każdej grupy asortymentowej, najczęściej jednak dotyczy to warzyw, owoców, mięsa i produktów garmażeryjnych oraz nabiału.

Rozważając problem znakowania i informacji na temat mięsa, warto zwrócić uwage na dziczyznę, czyli mięso oraz jadalne części tuszy zwierząt łownych. Podkreślić należy, że definicja dziczyzny ma charakter umowny, natomiast polskie prawo wskazuje jedynie gatunki zwierząt, których tusze można pozyskiwać realizując założenia łowiectwa, czas ich pozyskania oraz sposób, w jaki mogą zostać spożytkowane. (Rozporządzenie Ministra Środowiska w sprawie ustalenia listy gatunków zwierząt łownych, Ustawa Prawo łowieckie)

Dziczyzna budzi wśród konsumentów kontrowersje w aspekcie etycznym, ekologicznym, czy żywieniowym. Osoby funkcjonujące w sektorze podaży dziczyzny zwracają uwagę na trudny dostęp do rzetelnych informacji na temat dziczyzny (Kwiecińska i in., 2016). Problem dotyczy zarówno zakresu informacji, jak i okoliczności prezentacji takich treści. Respondenci twierdzili, że programy telewizyjne, w których promowano dziczyznę emitowane były w godzinach niskiej oglądalności, co wręcz uniemożliwiało dotarcie przekazu do szerokiego grona odbiorców. Podobnie w odniesieniu do publikacji w prasie wskazywano, że artykuły zawierające informacje o dziczyźnie ukazywały się jedynie w prasie branżowej, do której dostęp mają jedynie osoby związane z branżą 
mięsną lub łowiecką. Pod rozwagę należy poddać stwierdzenia respondentów, jakoby zwiększenie dostępności informacji na temat mięsa dzikich zwierząt może wpłynąć na wzrost spożycia dziczyzny przez polskich konsumentów. Warto także wspomnieć, że zainteresowanie dziczyzną deklarowane w badaniach nie przekłada się wielkość spożycia, które w Polsce utrzymuje się na poziomie marginalnym (Górecka i Szmańko, 2010).

Audycje o tematyce leśnej przedstawiają głównie funkcjonowanie lasu jako organizmu biologicznego, ale także mają na celu zapoznanie odbiorców głównie z specyfiką pracy leśników oraz zasadami funkcjonowania Państwowego Gospodarstwa Leśnego Lasy Państwowe. W sporadycznych przypadkach traktują o myślistwie, polityce łowieckiej, czy samej dziczyźnie jako produkcie spożywczym. Dziczyzna w roli składnika diety przedstawiana jest głównie $\mathrm{w}$ programach kulinarnych. Eksplorując ramowy program telewizyjny wskazać można, że przeciętny konsument codziennie ma możliwość obejrzenia przynajmniej jednego programu kulinarnego, w którym prezentowane są produkty, przepisy oraz porady dotyczące wyboru żywności, sposobu jej obróbki i inne aspekty związane z żywnością i żywieniem. Raport opublikowany przez KRRiT wskazuje, że w 2017 roku, w jednej z czterech najbardziej popularnych stacji, których udział w rynku to ok $10 \%$, w pierwszej dwudziestce audycji gromadzących największą liczbę widzów, znalazły się 3programy o tematyce kulinarnej (Najpopularniejsze audycje..., 2018). Jednak ilość programów, w których wykorzystywana jest dziczyzna jest znikoma. Oczywistym argumentem jest cena i dostępność dziczyzny. Audycja promująca produkty będące poza zasięgiem przeciętnego konsumenta ma mniejszą siłę oddziaływania - nie będzie więc emitowana w godzinach największej oglądalności.

Dla współczesnych konsumentów istotnym narzędziem komunikacji są także serwisy społecznościowe w Internecie. Rolę tego kanału komunikacji podkreśla mnogość profili stworzonych przez punkty sprzedaży, również sklepów $\mathrm{z}$ dziczyzną. Regularnie aktualizowana strona lub profil zapewnia nie tylko dostarczenie konsumentom najbardziej wiarygodnych informacji, ale także ułatwia kontakt $\mathrm{z}$ punktem np. poprzez czat lub wyświetlane w czasie rzeczywistym komentarze. Poprzez e-sklepy można również dziczyznę nabyć (Kwiecińska i in., 2017).

Konsumenci dziczyzny dodatkowo mogą zasięgnąc informacji na temat mięsa i jego sposobu obróbki od osób bezpośrednio związanych z pozyskaniem mięsa, tj. od myśliwych. Wiedza myśliwych natomiast, w dużej mierze przekazywana jest z pokolenia na pokolenie. Biorąc pod uwagę wiarygodność informacji, nieformalne źródła informacji cieszą się dużym zaufaniem konsumentów dziczyzny (Kwiecińska i in., 2017). Badania dowodzą także, że osoby z grona rodziny i znajomych myśliwych spożywają mięso dzikich zwierząt częściej niż osoby, które nie mają takich powiązań (Bodnar i wsp., 2014; Chardonnet i in., 2002).

Celem niniejszej publikacji było wskazanie głównych źródeł informacji mających wpływ na poziom wiedzy polskich konsumentów o dziczyźnie. Podjęto również próbę określenia zakresu informacji niezbędnych w procesie decyzyjnym, dotyczącym zakupu i konsumpcji dziczyzny.

\section{Materiały i metodyka}

W publikacji przestawiono wyniki ogólnopolskiego badania ilościowego, przeprowadzonego w grudniu 2016 roku. Badanie metodą wywiadów telefonicznych wspomaganych komputerowo (CATI) zrealizowano w grupie 450 respondentów. Próba 
badawcza odzwierciedlała reprezentatywność ilości mieszkańców w danym województwie, zgodnie z danymi Głównego Urzędu Statystycznego. Badanie kierowane było do osób deklarujących spożywanie dziczyzny. Z uwagi na niską zwrotność badania, osiąająca poziom 4\%, oraz brak danych źródłowych pozwalających skonstruować skalę częstości konsumpcji dziczyzny, parametr ten nie stanowił kryterium doboru próby. Jako dolną granicę wieku, w oparciu o dane GUS, wskazano 25 lat. Jest to wiek, w którym największy odsetek konsumentów tworzy odrębne gospodarstwo domowe, co przekłada się na zniwelowanie wpływu członków rodziny oraz wykształcenie własnych zachowań konsumenckich. Strukturę grupy badanej przedstawiono w tabeli 1.

Tabela 1. Charakterystyka grupy badanej

Table 1. Sample profile

\begin{tabular}{|c|c|c|}
\hline Kryterium & Liczba & Odsetek \\
\hline \multicolumn{3}{|l|}{ Wiek } \\
\hline $25-34$ lat & 167 & 37 \\
\hline $35-44$ lat & 122 & 27 \\
\hline $45-54$ lat & 111 & 25 \\
\hline Powyżej 55 lat & 50 & 11 \\
\hline \multicolumn{3}{|l|}{ Miejsce zamieszkania } \\
\hline Miasto & 246 & 55 \\
\hline Wieś & 204 & 45 \\
\hline \multicolumn{3}{|l|}{ Wykształcenie } \\
\hline Podstawowe & 11 & 2 \\
\hline Średnie/zawodowe & 348 & 77 \\
\hline Wyższe & 91 & 20 \\
\hline \multicolumn{3}{|l|}{ Powiązania } \\
\hline Respondent ma kontakt z osobami z sektora dziczyzny & 144 & 32 \\
\hline Respondent nie ma kontaktu z osobami z sektora dziczyzny & 306 & 68 \\
\hline
\end{tabular}

Źródło: badanie własne.

Parametrami charakteryzującymi respondentów była m.in. styczność z hodowcami zwierzyny, myśliwymi, oraz osobami zajmującymi się przetwórstwem oraz obrotem dziczyzną, a także własne doświadczenia w tym zakresie. W badanej grupie 10\% respondentów sama podejmowała działania związane z pozyskaniem, przetwórstwem lub obrotem dziczyzną. Blisko jedna trzecia respondentów deklarowała osobisty kontakt z myśliwymi lub przetwórcami i był to najczęściej członek rodziny lub osoba z kręgu znajomych.

Na potrzeby niniejszej publikacji, analizie poddano 3 pytania dotyczące informacji na temat dziczyzny: ich źródeł, zakresu oraz zaangażowania konsumentów. Pytanie dotyczące aktywnego poszukiwania informacji opatrzono skalą dychotomiczną. Istotność poszczególnych źródeł wiedzy pozyskiwanej bądź poszukiwanej respondenci określali w pięciostopniowej skali Likerta, zakres informacji określano w skali trzystopniowej, uwzględniając ich istotność. Do przeprowadzenia analizy statystycznej wykorzystano tabele krzyżowe, analizę częstości, określono poziom istotności oraz współczynnik korelacji Pearsona. 


\section{Wyniki badań}

\section{Wykorzystywane źródła informacji}

W toku badania respondenci zostali poproszeni o wskazanie, czy poszukują informacji o dziczyźnie w sposób aktywny - podejmują świadome kroki w tym celu, czy też informacje takie docierają do nich mimowolnie. Ponad $84 \%$ badanych przyznało, że nie podejmuje działań, mających na celu poszerzenie wiedzy związanej z zakupem i konsumpcja mięsa dzikich zwierząt. Przyczyny można szukać w niskiej dostępności informacji, co wyraźnie podkreślają myśliwi i osoby działające w sektorze podażowym rynku mięsa (Kwiecińska i in., 2016).

Uwzględniając socjodemograficzne cechy respondentów podkreślić należy, że poszukiwanie wiadomości deklarowało $21 \%$ mieszkańców wsi i jedynie $11 \%$ mieszkańców miasta. Wskazano, że informacji częściej poszukiwały osoby pomiędzy 34 a 55 rokiem życia, natomiast uwzględniając poziom wykształcenia stwierdzono, że większą aktywność deklarowały osoby z wykształceniem podstawowym. Co ciekawe, respondenci mający w swoim najbliższym otoczeniu osobę funkcjonującą w branży dziczyzny, częściej niż osoby niezwiązane z sektorem poszukiwały informacji, choć różnica dla obu grupy wynosiła jedynie $5 \%$. Przeprowadzona analiza nie wykazała zależności istotnej statystycznie między cechami respondentów a aktywnym poszukiwaniem informacji na temat dziczyzny.

Kolejną kwestią podniesioną w badaniu były źródła, z jakich konsument potencjalnie może uzyskać informacje, niezależnie od tego, czy podejmował w tym celu świadome działanie. Podkreślić należy, że współczesny konsument jest otoczony chmurą informacji i nie zawsze zdobywanie wiedzy wymaga od niego zaangażowania. W tabeli 2 przedstawiono zależności między cechami konsumenta i wykorzystywanymi źródłami informacji.

Tabela 2. Wpływ wybranych cech respondenta na wybór kanału informacji

Table 2. The effect of respondent's features on their choice of the information source

\begin{tabular}{l|cccccccc}
\hline \multirow{2}{*}{$\begin{array}{l}\text { Skąd respondent czerpie } \\
\text { informacje }\end{array}$} & \multicolumn{2}{c}{ Wiek } & \multicolumn{2}{c}{ Wykształcenie } & \multicolumn{2}{c}{$\begin{array}{c}\text { Miejsce } \\
\text { zamieszkania }\end{array}$} & \multicolumn{2}{c}{ Powiązania } \\
& $\mathrm{r}$ & $\mathrm{p}$-value & $\mathrm{r}$ & $\mathrm{p}$-value & $\mathrm{r}$ & $\mathrm{p}$-value & $\mathrm{r}$ & $\mathrm{p}$-value \\
\hline z programów kulinarnych & 0,106 & $0,025^{*}$ & $-0,109$ & $0,021^{*}$ & $-0,019$ & 0,682 & $-0,056$ & 0,238 \\
z Internetu & $-0,032$ & 0,501 & $-0,031$ & 0,519 & $-0,013$ & 0,780 & 0,146 & $0,002^{*}$ \\
od rodziny i znajomych & 0,038 & 0,417 & $-0,149$ & $0,002^{*}$ & 0,040 & 0,396 & 0,000 & 0,996 \\
od lekarzy i specjalistów & 0,033 & 0,488 & $-0,020$ & 0,675 & 0,016 & 0,743 & 0,122 & $0,010^{*}$ \\
od sprzedawcy & 0,113 & $0,016^{*}$ & $-0,025$ & 0,591 & $-0,011$ & 0,811 & 0,009 & 0,849 \\
z etykiet i opakowań & $-0,018$ & 0,702 & $-0,028$ & 0,561 & 0,031 & 0,518 & 0,039 & 0,407 \\
z reklamy & $-0,058$ & 0,221 & 0,039 & 0,407 & $-0,074$ & 0,118 & 0,009 & 0,849 \\
z ulotek sklepowych & $-0,088$ & 0,063 & 0,131 & $0,005^{*}$ & 0,015 & 0,759 & 0,016 & 0,740 \\
z artykułów prasowych & 0,022 & 0,645 & 0,086 & 0,068 & $-0,028$ & 0,554 & $-0,004$ & 0,934 \\
z książek kulinarnych & $-0,041$ & 0,390 & $-0,001$ & 0,976 & 0,050 & 0,288 & 0,121 & $0,010^{*}$ \\
od obsługi w restauracji & $-0,066$ & 0,161 & $-0,089$ & 0,060 & 0,072 & 0,127 & 0,124 & $0,008^{*}$ \\
\hline
\end{tabular}

gdzie: $\mathrm{r}$ - współczynnik korelacji Pearsona, * - istotne statystycznie przy p <0,05.

Źródło: badanie własne. 
Wyniki badania nie wskazują istotnych statystycznie powiązań między miejscem zamieszkania respondenta a źródłami informacji na temat dziczyzny. Co ciekawe, mieszkańcy miast cześciej korzystali $\mathrm{z}$ informacji umieszczanych $\mathrm{w}$ prasie oraz przekazywanych $\mathrm{w}$ formie reklam, ale rzadziej zasięgali opinii od pracowników lokali gastronomicznych, niż mieszkańcy wsi. Podkreślić należy, że mieszkańcy miast znacznie częściej spożywali dziczyznę w lokalach gastronomicznych niż mieszkańcy wsi. Blisko $26 \%$ mieszkańców miast wskazało, że najczęściej dziczyznę spożywa w restauracjach, podczas gdy dla mieszkańców wsi odsetek ten wyniósł $12 \%$. Sposób określenia istotności pozostałych źródeł informacji nie wskazał znaczących różnic między postawami mieszkańców wsi i miast.

W odniesieniu do wieku respondentów wykazano, że w istotny sposób decydował on o wyborze źródeł informacji, takich jak programy kulinarne dostępne w mediach oraz pozyskiwanie danych od sprzedawców. Podkreślić należy, że najczęściej wybieranym przez badanych źródłem informacji o dziczyźnie są programy kulinarne prezentowane w telewizji. Wiedzę o dziczyźnie $\mathrm{z}$ tego medium czerpie co piąty respondent $\mathrm{w}$ wieku powyżej 50 lat. W opozycji stoi grupa badanych w wieku od 25 do 34 lat, z których jedynie $12 \%$ wskazało istotność źródła informacji na poziomie 4 i 5.

W przypadku wskazanych skrajnych grup: najstarszych i najmłodszych uczestników badania, uzyskano interesujące wyniki dotyczące poszukiwania danych w Internecie. Choć wydawać by się mogło, że z tego medium korzystają młodsi konsumenci, w odniesieniu do dziczyzny, jest to znacznie mniejszy odsetek niż w grupie osób w wieku 55 lat i więcej. Najmłodsi respondenci, częściej niż osoby z najstarszej grupy badanych, zasięgali informacji od lekarzy i specjalistów, korzystali z ulotek oraz wiadomości z prasy. Nie wykazano jednak zależności istotnej statystycznie.

Z perspektywy prowadzonych badań ciekawe źródło informacji stanowi prasa. Kwiecińska i in. (2016) wskazują, że zdaniem grupy „ekspertów”, działających aktywnie w sektorze podażowym rynku dziczyzny, informacje na temat dziczyzny w prasie nie są dostępne dla przeciętnego konsumenta. Publikowane są głównie w czasopismach branżowych, kierowanych do myśliwych, pracowników sektora leśnego, czy osób związanych z rynkiem spożywczym, w tym rynkiem mięsa. Zdaniem „ekspertów” w ogólnodostępnej prasie pojawiają się sporadycznie, głównie w czasie świąt religijnych i przygotowań do tych wydarzeń, kiedy dieta i decyzje zakupowe konsumentów zmieniaja się na krótki czas. Myśliwi i osoby zajmujące się obrotem dziczyzną wskazują, że w tych okresach również wzrasta popyt na dziczyznę, uznawaną przez konsumentów za produkt luksusowy (Kwiecińska $\mathrm{i}$ in., 2016). Z perspektywy psychologii konsumpcji, wybór produktu niekonsumowanego na co dzień, o wyższej wartości i odmiennych cechach, może służyć do pokreślenia pozycji społecznej (Jaworski i Fabisiak, 2017). Spożywanie obfitych, wyszukanych potraw, np. z droższych, trudnodostępnych produktów często służy podkreśleniu rangi wydarzenia (Makała, 2014). Wśród konsumentów dziczyzny, jedynie co piąty respondent wskazał, że $\mathrm{w}$ jego gospodarstwie domowym dziczyznę przyrządza się wyłącznie na specjalne okazje. Regularna konsumpcja produktu może niwelować jego symboliczne znaczenie.

Przeprowadzone badanie empiryczne pozwoliło na stwierdzenie, że osoby mające kontakt z myśliwymi, hodowcami zwierzyny lub przetwórcami dziczyzny, poszukiwały informacji o dziczyźnie u rodziny i znajomych. W dalszej kolejności za istotne źródła wiedzy o dziczyźnie wymieniano sprzedawców, a także informacje umieszczone na etykiecie. Warto również wskazać, że 12\% respondentów deklarowało kupno, a $9 \%$ 
badanych bezpłatnie otrzymywało dziczyznę bezpośrednio od myśliwego. Kontynuując: $12 \%$ zakupiło, a $33 \%$ respondentów otrzymało mięso za darmo od członka rodziny. Uwzględniając taki rodzaj nabywania produktu uznać należy, że przekazywanie wiedzy i informacji o dziczyźnie jest nierozerwalnie związane z jej dystrybucją. Również rola sprzedawców w sklepach jest niepodważalna $-59 \%$ ogółu respondentów wskazało, że z ich wiedzy korzysta bardzo chętnie. Co ciekawe, w odniesieniu do żywności ogółem, jedynie $8 \%$ respondentów wskazało opinię sprzedawcy, jako czynnik wpływający na ich wybory rynkowe (Maciejewski, 2011).

Najwyższy odsetek odpowiedzi dotyczących istotności źródeł informacji odnotowano dla treści umieszczonych na etykiecie produktu, co jest zgodne $\mathrm{z}$ wynikami badań prowadzonymi wśród konsumentów na rynku żywności. Jak wskazały Ozimek i Tomaszewska (2011) na szczycie hierarchii istotności informacji o żywności znajdują się te, umieszczane na opakowaniu produktu. Uważne czytanie etykiet było też jednym z głównych sposobów ograniczania poziomu ryzyka zarażenia się chorobą odzwierzęca, wskazywanych przez konsumentów dziczyzny (Kwiecińska i in., 2015).

\section{Zakres informacji}

Wskazane cechy socjoekonomiczne charakteryzujące konsumentów wpływały nie tylko na sposób pozyskiwania informacji o dziczyźnie, ale także na ich zakres. W tabeli 3 przedstawiono odsetek respondentów, wskazujący wybrane kategorie najczęściej pozyskiwanych informacji na temat dziczyzny.

Tabela 3. Wpływ wybranych cech respondenta na treść najczęściej pozyskiwanych informacji (w \%)

Table 3. The influence of selected respondent's features on the content of the most frequently obtained information

\begin{tabular}{|c|c|c|c|c|c|c|c|c|c|c|}
\hline \multirow{3}{*}{ Zakres informacji } & \multicolumn{9}{|c|}{ Cechy respondenta } & \multirow{3}{*}{$\begin{array}{l}\text { Łącznie } \\
\text { z N=450 }\end{array}$} \\
\hline & \multicolumn{4}{|c|}{ Wiek w latach } & \multicolumn{3}{|c|}{ Wykształcenie } & \multicolumn{2}{|c|}{$\begin{array}{c}\text { Miejsce } \\
\text { zamieszkania }\end{array}$} & \\
\hline & $25-34$ & $35-44$ & $45-54$ & $>55$ & I & II & III & Miasto & Wieś & \\
\hline Termin przydatności & 44,9 & 42,6 & 54,1 & 52,0 & 72,7 & 44,8 & 53,8 & 55,7 & 37,3 & 47,3 \\
\hline Sposób obróbki & 18,0 & 27,0 & 31,5 & 26,0 & 27,3 & 22,1 & 34,1 & 26,8 & 22,1 & 24,7 \\
\hline Wartość odżywcza & 14,4 & 20,5 & 15,3 & 20,0 & 18,2 & 13,8 & 28,6 & 19,9 & 13,2 & 16,9 \\
\hline Wpływ na zdrowie & 17,4 & 27,9 & 22,5 & 18,0 & 18,2 & 17,8 & 36,3 & 24,8 & 17,6 & 21,6 \\
\hline Sposób pozyskania & 17,4 & 30,3 & 28,8 & 24,0 & 36,4 & 23,9 & 25,3 & 26,4 & 22,1 & 24,4 \\
\hline Pochodzenie & 27,5 & 32,8 & 41,4 & 32,0 & 45,5 & 33,3 & 29,7 & 38,2 & 26,5 & 32,9 \\
\hline Cena & 38,9 & 31,1 & 42,3 & 26,0 & 54,5 & 35,6 & 36,3 & 41,9 & 29,4 & 36,2 \\
\hline Miejsce zakupu & 22,8 & 22,1 & 26,1 & 10,0 & 54,5 & 20,7 & 23,1 & 27,2 & 15,7 & 22,0 \\
\hline
\end{tabular}

gdzie: I - podstawowe, II - średnie/zawodowe, III - wyższe;

Źródło: badanie własne.

W odniesieniu do badanej próby stwierdzono, że konsumenci za najbardziej istotne uznali informacje na temat terminu przydatności do spożycia oraz ceny dziczyzny. Wykazano również, że mieszkańcy wsi określali istotność każdej kategorii informacji 
na poziomie niższym niż respondenci z miasta. W przypadku każdej kategorii informacji wykazano zależność statystyczną (tabela 4). Wiek natomiast nie wpływał w istotny sposób na zachowania konsumentów w odniesieniu do poszukiwanych informacji.

Tabela 4. Zależność między wybranymi cechami respondenta a treścią pozyskiwanych informacji

Table 4. The effect of respondent's features on their choice of the information content

\begin{tabular}{|c|c|c|c|c|c|c|c|c|}
\hline \multirow{3}{*}{ Zakres informacji } & \multicolumn{8}{|c|}{ Cechy respondenta } \\
\hline & \multicolumn{2}{|c|}{ Wiek } & \multicolumn{2}{|c|}{ Wykształcenie } & \multicolumn{2}{|c|}{$\begin{array}{c}\text { Miejsce } \\
\text { zamieszkania }\end{array}$} & \multicolumn{2}{|c|}{ Powiązania } \\
\hline & $\mathrm{r}$ & p-value & $\mathrm{r}$ & $\mathrm{p}$-value & $\mathrm{r}$ & $\mathrm{p}$-value & $\mathrm{r}$ & $\mathrm{p}$-value \\
\hline Termin przydatności & 0,045 & 0,341 & 0,002 & 0,962 & $-0,220$ & $0,000 *$ & $-0,113$ & $0,017 *$ \\
\hline Sposób obróbki & 0,091 & 0,054 & 0,015 & 0,755 & $-0,124$ & $0,009 *$ & 0,006 & 0,899 \\
\hline Wartość odżywcza & 0,029 & 0,538 & 0,086 & 0,068 & $-0,166$ & $0,000^{*}$ & 0,024 & 0,608 \\
\hline Wpływ na zdrowie & 0,040 & 0,397 & 0,097 & $0,040 *$ & $-0,161$ & $0,001 *$ & $-0,004$ & 0,938 \\
\hline Sposób pozyskania & 0,070 & 0,138 & $-0,069$ & 0,142 & $-0,119$ & $0,012^{*}$ & $-0,058$ & 0,218 \\
\hline Pochodzenie & 0,063 & 0,183 & $-0,063$ & 0,182 & $-0,178$ & $0,000 *$ & $-0,045$ & 0,339 \\
\hline Cena & $-0,024$ & 0,607 & $-0,031$ & 0,511 & $-0,194$ & $0,000^{*}$ & $-0,138$ & $0,003 *$ \\
\hline Miejsce zakupu & 0,003 & 0,947 & $-0,113$ & $0,017^{*}$ & $-0,194$ & $0,000 *$ & $-0,028$ & 0,560 \\
\hline
\end{tabular}

gdzie: r - współczynnik korelacji Pearsona, * - istotne statystycznie przy p $<0,05$.

Źródło: badanie własne.

Niezależnie od cech charakteryzujących respondenta, najrzadziej poszukiwanymi danymi na temat dziczyzny były: wartość odżywcza, wpływ tego rodzaju mięsa na zdrowie oraz miejsce zakupu. Uzyskane wyniki uzasadniać może poziom świadomości osób spożywających dziczyznę, wybierających tego rodzaju produkt właśnie z uwagi na jego parametry fizykochemiczne oraz znaczenie żywieniowe. Odnosząc się do miejsca zakupu dziczyzny wskazać należy, iż jedynie $10 \%$ respondentów deklarowało poszukiwanie nowych miejsc, gdzie nabyć można mięso oczekiwanej jakości. Jak wskazuje Kwiecińska $\mathrm{i}$ in. (2015), nabywanie dziczyzny w sprawdzonym, znanym miejscu, stanowi, podobnie jak czytanie etykiet, sposób redukcji ryzyka narażenia konsumenta na zagrożenia związanie z konsumpcją mięsa. Poczucie bezpieczeństwa jest więc istotnym aspektem determinującym zachowania nabywcze.

\section{Podsumowanie}

Wraz z rozwojem technologii zmienia się sposób przekazywania danych, co z kolei stanowi katalizator zmian $\mathrm{w}$ zachowaniach żywieniowych konsumentów. Informacje nie przepływają w jednym kierunku, ale tworzą skomplikowaną sieć, w której znajdują się konsumenci, producenci, dystrybutorzy i wiele innych ogniw rynku. Konsumenci dziczyzny jedynie w niewielkiej części wykazują aktywność związaną ze zdobywaniem nowych informacji na temat mięsa. Mimo braku zaangażowania takie informacje jednak do nich docieraja, a ich dostępność wydaje się większa, niż wskazywana przez myśliwych i osoby z sektora podaży, co wskazywano w przytoczonych w badaniach. 
Dowiedziono, że istotną rolę $\mathrm{w}$ przekazywaniu informacji na temat dziczyzny odgrywają członkowie rodziny i znajomi. Czynnik ten powinien zostać uwzględniony podczas kreowania koncepcji programów oraz materiałów promocyjnych dotyczących dziczyzny. Istotne jest, aby podane treści były zrozumiałe dla potencjalnego odbiorcy, co przełożyć się może na łatwe przekazanie zdobytej wiedzy kolejnym interlokutorom.

Istotna rola etykiet $\mathrm{w}$ dostarczaniu informacji nie jest specyficzna dla dziczyzny. W kontekście wyrobów z mięsa dzikich zwierząt uzasadnione wydaje się jednak zwrócenie szczególnej uwagi na wymiar graficzny opakowania oraz etykiety, jako jej integralnej części. Na zainteresowanie konsumentów dziczyzną wpływ może mieć przedstawienie symboli i ilustracji powszechnie kojarzących się z lasem, naturalnym środowiskiem bytowania zwierzyny. Istotne jest również wyeksponowanie na etykiecie informacji dotyczących pochodzenia produktu oraz jego terminu przydatności do spożycia, ponieważ są to informacje poszukiwane przez nabywców dziczyzny. Dodatkowym udogodnieniem dla konsumentów może być umieszczenie informacji dotyczących dalszej obróbki mięsa, co mogłoby ułatwić nabywcom podjęcie decyzji o zakupie produktu. Brak wiedzy na temat przydatności kulinarnej mięsa zwierząt łownych może stanowić czynnik ograniczający zainteresowanie produktem.

Przeprowadzone badanie ilościowe potwierdziło znaczącą rolę materiałów informacyjnych, dostępnych w punktach sprzedaży, oraz informacji przekazywanych przez sprzedawców. Ponieważ konsumenci nabywają dziczyznę w punktach różnego typu, trudno jest zdefiniować uniwersalny zbiór zasad, jakimi kierować powinni się sprzedawcy. Punktem wspólnym natomiast powinna być treść oraz rzetelność informacji, a także przystępny sposób ich przekazywania. W kwestii kompozycji i treści materiałów informacyjnych wdrożone mogą zostać założenia odnoszące się do etykiet.

W kontekście najmniej popularnych źródeł informacji na temat dziczyzny podkreślić należy niewykorzystany potencjał medium jakim jest telewizja. Wśród zaleceń dotyczących tego kanału informacji wskazać można prezentację treści w czasie wysokiej oglądalności. Kluczowe również okazać się może przedstawienie i wyjaśnienie tematyki dziczyzny uwzględniając aspekty prawne, żywieniowe, łowieckie, a finalnie kulinarne. Holistyczne ujęcie zagadnienia mogłoby się przyczynić do zmiany postrzegania łowiectwa przez konsumentów oraz wzrostu zainteresowania tematyką dziczyzny.

\section{Literatura}

Bodnar, K., Szel Hodi, M., Skobrak Bodnar, E. (2014). Acceptance of the meat of wild ungulates among the hungarian consumers. Agronomy Series of Scientific Research/Lucrari Stiintifice Seria Agronomie, 57(1), 35-38.

Chardonnet, P., Clers, B.D., Fischer, J., Gerhold, R., Jori, F., Lamarque, F. (2002). The value of wildlife. Revue scientifique et technique-Office international des epizooties, 21(1), 15-51.

Górecka, J., Szmańko, T. (2010). Walory żywieniowe dziczyzny (Nutritional value of game meat). Magazyn Przemystu Mięsnego, 1-2, 20-21.

Jaworski, M., Fabisiak, A. (2017). Psychospołeczne determinanty wyboru żywności (Psychosocial determinants of choice of the food). Zeszyty Naukowe Uczelni Vistula, (54 (3) Turystyka III), 17-29.

Kłosiewicz-Górecka, U., Słomińska, B. (2005). Informacja w budowaniu pozycji rynkowej małej i średniej firmy (Information in building the market position of small and medium-sized company). Wydawnictwo Instytutu Rynku Wewnętrznego i Konsumpcji, Warszawa.

Kwiecińska, K., Kosicka-Gębska, M., Gębski, J. (2015). Poziom bezpieczeństwa jako czynnik warunkujący konsumpcję dziczyzny (Safety level as a factor determining venison consumption). Problemy Higieny $i$ Epidemiologii, 96(3), 594-597. 
Kwiecińska, K., Kosicka-Gębska, M., Gębski, J. (2016). Wyzwania dla rozwoju rynku dziczyzny w Polsce (Challenges for the development of the game market in Poland). Problemy Rolnictwa Światowego, 16(31), 251-260.

Kwiecińska, K., Kosicka-Gębska, M., Gębski, J. (2017). Wpływ tradycji rodzinnych na zachowania konsumentów wobec dziczyzny (Effect of family tradition on consumers behaviour towards game meat). Studia Ekonomiczne, 330, 86-95.

Maciejewski, G. (2010). Ryzyko w decyzjach nabywczych konsumenta (Risk in consumer purchasing decisions), Wydawnictwo Uniwersytetu Ekonomicznego w Katowicach, Katowice.

Maciejewski, G. (2011). Ryzyko jako determinanta zachowań zakupowych konsumentów (Risk as a determinant of consumer purchasing behaviour). Studia i Materiaty Polskiego Stowarzyszenia Zarzqdzania Wiedza, 52, $85-96$.

Makała, H. (2014). Kultura żywieniowa a turystyka-obszary wspólnych zainteresowań (A food culture tourism areas of common interests). Zeszyty Naukowe. Turystyka i Rekreacja, 1(13), 133-145.

Ozimek, I., Tomaszewska, M. (2011). Znaczenie wybranych źródeł informacji o produktach żywnościowych dla konsumentów (Importance of selected sources of food information for consumers). Handel Wewnętrzny, 2(331), 48-56

Rudnicki, L. (2000). Zachowanie konsumentów na rynku (Consumer behaviour on the market). Polskie Wydawnictwo Ekonomiczne, Warszawa.

Akty prawne:

Rozporządzenie Ministra Środowiska z dnia 11 marca 2005 r. w sprawie ustalenia listy gatunków zwierząt łownych (Dz.U. 2005 nr 45 poz. 433) z późn. zm.

Ustawa z dnia 13 października 1995 r. Prawo łowieckie (Dz.U. 1995 nr 147 poz. 713) z późn. zm.

Opracowanie dostępne online:

Najpopularniejsze audycje w 2017 roku. Dobowa oglądalność programów - raport. Pobrane 1 czerwca 2018 r. z: http://www.krrit.gov.pl/Data/Files/_public/Portals/0/kontrola/program/tv/problemowe/najpopularniejszeaudycje-w-2017-r.dobowa-ogladalnosc-programow.pdf, dostęp: 01.06.2018.

Do cytowania / For citation:

Kwiecińska K., Kosicka-Gębska M., Gębski J. (2018). Wpływ wybranych źródeł informacji na poziom wiedzy konsumentów o dziczyźnie. Problemy Rolnictwa Światowego, 18(4), 313-322; DOI: $10.22630 /$ PRS.2018.18.4.121

Kwiecińska K., Kosicka-Gębska M., Gębski J. (2018). Influence of Selected Information Sources on the Level of Consumers Awareness of Game Meat (in Polish). Problems of World Agriculture, 18(4), 313-322; DOI: 10.22630/PRS.2018.18.4.121 